\title{
Ebola virus outbreaks in Africa: Past and present
}

\author{
Authors: \\ J.J. Muyembe-Tamfum ${ }^{1,2}$ \\ S. Mulangu ${ }^{3,4}$ \\ Justin Masumu ${ }^{1,3}$ \\ J.M. Kayembe 2 \\ A. Kemp ${ }^{5}$ \\ Janusz T. Paweska ${ }^{5}$ \\ Affiliations: \\ ${ }^{1}$ Institut national de \\ Recherche Biomédicale, \\ Kinshasa I, Democratic \\ Republic of the Congo \\ ${ }^{2}$ Université de Kinshasa, \\ Kinshasa XI, Democratic \\ Republic of the Congo \\ ${ }^{3}$ Southern African Centre \\ for Infectious Disease \\ Surveillance, Chuo Kiikuu, \\ Tanzania \\ ${ }^{4}$ National Institute of Allergy \\ and Infectious Diseases, \\ National Institutes of Health, \\ United States
}

${ }^{5}$ Special Pathogens Unit, National Institute for Communicable Diseases of the National Health Laboratory Service, South Africa

Correspondence to: Justin Masumu

Email:

justin.masumu@sacids.org

Postal address:

PO Box 3297, Chuo Kikuu

Morogoro, Tanzania

How to cite this proceeding: Muyembe-Tamfum, J.J., Mulangu, S., Masumu, J., Kayembe, J.M., Kemp, A. \& Paweska, J.T., 2012, 'Ebola virus outbreaks in Africa: Past and present', Onderstepoort Journal of Veterinary Research 79(2), Art. \#451, 8 pages. http://dx.doi. org/10.4102/ojvr.v79i2.451

Note:

Proceedings of the Conference of the Southern African Centre for Infectious Disease Surveillance 'One Health' held at the National Institute for Communicable Diseases, Johannesburg, July 2011.
Ebola haemorrhagic fever (EHF) is a zoonosis affecting both human and non-human primates (NHP). Outbreaks in Africa occur mainly in the Congo and Nile basins. The first outbreaks of EHF occurred nearly simultaneously in 1976 in the Democratic Republic of the Congo (DRC, former Zaire) and Sudan with very high case fatality rates of $88 \%$ and $53 \%$, respectively. The two outbreaks were caused by two distinct species of Ebola virus named Zaire ebolavirus (ZEBOV) and Sudan ebolavirus (SEBOV). The source of transmission remains unknown. After a long period of silence (1980-1993), EHF outbreaks in Africa caused by the two species erupted with increased frequency and new species were discovered, namely Côte d'Ivoire ebolavirus (CIEBOV) in 1994 in the Ivory Coast and Bundibugyo ebolavirus (BEBOV) in 2007 in Uganda. The re-emergence of EHF outbreaks in Gabon and Republic of the Congo were concomitant with an increase in mortality amongst gorillas and chimpanzees infected with ZEBOV. The human outbreaks were related to multiple, unrelated index cases who had contact with dead gorillas or chimpanzees. However, in areas where NHP were rare or absent, as in Kikwit (DRC) in 1995, Mweka (DRC) in 2007, Gulu (Uganda) in 2000 and Yambio (Sudan) in 2004, the hunting and eating of fruit bats may have resulted in the primary transmission of Ebola virus to humans. Human-to-human transmission is associated with direct contact with body fluids or tissues from an infected subject or contaminated objects. Despite several, often heroic field studies, the epidemiology and ecology of Ebola virus, including identification of its natural reservoir hosts, remains a formidable challenge for public health and scientific communities.

\section{Introduction}

The first Southern African Centre for Infectious Disease Surveillance (SACIDS) conference on 'One Africa, One Health' served as inspiration for this review to illustrate the concept through a typical emerging infection. Ebola haemorrhagic fever (EHF) is caused by any of five genetically distinct members of the Filoviridae family: Zaire ebolavirus (ZEBOV), Sudan ebolavirus (SEBOV), Côte d'Ivoire ebolavirus (CEBOV), Bundibugyo ebolavirus (BEBOV) and Reston ebolavirus (REBOV). Côte d'Ivoire ebolavirus has been associated with only one human case (Le Guenno et al. 1995). Reston ebolavirus has only caused disease in non-human primates (NHP) and was found in swine suffering from porcine reproductive and respiratory disease syndrome (Barrette et al. 2009). Zaire, Sudan and Bundibugyo Ebola viruses are responsible for most of the EHF outbreaks (Feldmann et al. 2005; Groseth, Feldmann \& Strong 2007; Towner et al. 2008) but ZEBOV constitutes a particularly serious threat to both human and NHPs in sub-Saharan Africa. Ebola haemorrhagic fever has been associated with large human outbreaks, with case fatality rates for ZEBOV as high as $90 \%$. The case fatality rate of EBOV in NHP is unknown but some ecological data suggest that EBOV has contributed to declines of up to $98 \%$ of local great ape populations in Gabon and the Republic of Congo (Walsh et al. 2003).

Currently there are no approved antiviral drugs or vaccines against filoviruses. The prevention of EHF requires improving our understanding of the epidemiology of the disease, especially the role of wildlife, including bats, in the transmission of Ebola virus to humans. In their exhaustive review on Ebola virus, Feldmann and Geisbert (2011) tackled different fundamental aspects of EHF outbreaks. Leroy, Gonzalez and Baize (2011) reviewed the major scientific advances in our understanding of the ecology, host interactions, and control of the Ebola and Marburg viruses. In the present review we report important features related to Ebola outbreaks in Africa based on previous findings and own observations during major outbreaks that occurred on the continent.

\section{Documented human and non-human primate outbreaks in Africa}

Ebola viruses constitute a serious threat to both human and wildlife health in the Congo and Nile basins. The first documented outbreaks were generally regarded as causing a mysterious

Copyright: ( 2012. The Authors. Licensee: AOSIS OpenJournals. This work is licensed under the Creative Commons Attribution License. 
disease, so dramatic in its effect that it inspired novelists and film producers. In most of the cases, the disease has appeared suddenly out of the elusive natural environment and dissipated slowly during the outbreak. The first outbreaks of EHF occurred almost simultaneously in 1976 in southern Sudan (June) and northwestern Zaire (now Democratic Republic of the Congo, DRC) (September). Initially it was thought that the DRC outbreak was due to dissemination of the Sudan outbreak but, in fact, the outbreaks were caused by two antigenically and biologically distinct species named SEBOV and ZEBOV. The index case in Sudan was a worker in a cotton factory in Nzara who subsequently was the source of nosocomial transmission in Maridi hospital. The mortality rate amongst the 284 notified cases was 53\% (WHO 1978a). The index case in the Zaire or DRC outbreak was a 44 year-old male instructor at the Yambuku catholic mission school who fell ill after extensive travels in northern Equateur Province. He bought fresh and smoked antelope and monkey meat on his way back to Yambuku. He was treated for presumptive malaria at the Yambuku hospital, where the outbreak emerged subsequently. In total 318 cases were recorded, with a case fatality rate of $88 \%$. Close contact with an acute Ebola case and receiving an injection with a reused, unsterilised syringe at the hospital were the major risk factors for virus transmission in humans (WHO 1978b).

In 1979, Nzara and Maridi in Sudan were again hit by a small outbreak, with 34 cases and 22 deaths (Baron, McCormick \& Zubeir 1983), whereas a single case was described in a child at Tandala hospital in DRC (Heymann et al. 1980). Apparently, none of the cases had contact with wild animals.

After an absence from 1980 to 1993, several independent foci of Ebola virus transmission were recorded. Most of them were caused by ZEBOV and SEBOV but some were caused by the newly discovered species, namely CIEBOV and BEBOV:

- Ebola haemorrhagic fever in Côte d'Ivoire (1994): A large Ebola virus outbreak occurred amongst chimpanzees living in the Taï National Park in Côte d'Ivoire. An ethologist was infected whilst performing an autopsy on a dead chimpanzee. The patient was treated as a presumptive malaria case in Abidjan hospital, without success. There were no secondary cases. This was the first documented outbreak of Ebola virus amongst NHP in nature and the first in West Africa. The outbreak led to the discovery of a new species of Ebola virus, namely CIEBOV (Le Guenno et al. 1995).

- Ebola haemorrhagic fever in Gabon (1994, 1996, 1997 and 2001-2002): Several viral haemorrhagic fever outbreaks, caused by ZEBOV, were associated with the hunting of NHP. The 1994 outbreak involved gold-diggers in the Minkebé Forest who had killed a sick gorilla for food; the illness was initially confused with yellow fever (Amblard et al. 1997; Georges-Courbot et al. 1997a, 1997b; Leroy et al. 2002).

- Ebola haemorrhagic fever in the Republic of the Congo (2001-2002, 2003 and 2005): The first recorded outbreak of
Ebola occurred in 2001-2002. In 2003, ZEBOV re-emerged, affecting 143 individuals in Mbomo (17 cases) and Kellé (126 cases), and 128 deaths were recorded (Formenty et al. 2006). Three independent index cases were identified in relation to hunting episodes and contact with gorillas. During this outbreak, intra-familial transmission was more important than nosocomial transmission. However, three health care workers were infected. In the same year, another small Ebola outbreak, involving 35 cases and 29 deaths, had occurred. The last documented Ebola outbreak in the country was reported in 2005, with 11 cases and nine deaths (Nkoghe et al. 2011).

- Ebola haemorrhagic fever in the DRC (1995): ZEBOV reemerged in 1995 in the city of Kikwit, with 400000 inhabitants, $1000 \mathrm{~km}$ south of the location of the 1976 outbreak. In total, 315 cases and 250 deaths were recorded. A 31-year-old female Ebola patient traveled during the early stage of her disease to Kinshasa, where she was isolated in a private clinic. No secondary transmission occurred (Khan et al. 1999). The main occupation of the index case was farming and preparing charcoal in one of the remnant forest areas near Kikwit but the exact cause of infection or exposure is not known. There were no great apes but a lot of bats and rodents were present in the region. The risk factors for secondary human-to-human infection were mainly working in Kikwit general hospital or preparing corpses for burial. Almost $20 \%$ of the 250 victims were health care workers (Guimard et al. 1999).

- Ebola haemorrhagic fever in the DRC (2007-2008, 20082009): A further outbreak occurred in 2007, in the Mweka health zone, West Kasai Province, involving 264 cases and 187 deaths with a case fatality rate (CFR) of $71 \%$. Kampungu city was the epicenter of the outbreak with $47 \%$ of cases, followed by the city of Kaluamba ( $42 \%$ of cases). The index case was the chief of the village and a hunter. The outbreak was apparently associated with a massive fruit bat migration through this region (Leroy et al. 2007). During this outbreak, the fatalities amongst health care workers were fewer. However, several humanto-human transmissions had occurred in churches where patients had been taken for prayers and nursing (Doctors Without Borders, unpublished data).

- In the 2008 Ebola outbreak, Kaluamba was affected again, with 32 cases and 14 deaths (CFR of $43.8 \%$ ). The index case was believed to be an 18 year old girl who had died from a post-abortion haemorrhage. However, the source of her exposure remains unknown. This outbreak was reported to the national and provincial health authorities 21 days after the disease onset, compared to a period of four months in the 2007 epidemic. The observed low CFR in Kaluamba outbreak is considered to be due to the early recognition of the disease and the prompt response of the national team.

- Ebola haemorrhagic fever in Uganda (2000, 2007, 2011): An outbreak of SEBOV occurred in Gulu in 2000 and spread to the cities of Mbarara and Masindi, with a total of 425 cases and 224 deaths (CFR of 52\%) (Lamunu et al. 2004). This was the largest epidemic caused by SEBOV. The outbreak was recognised from a cluster of human cases and was amplified by nosocomial transmission. Uganda was again affected in 2007 when a new Ebola species, 
BEBOV, killed 30 people out of 116 cases (CFR of 26\%) (Towner et al. 2008). An isolated case of EHF caused by SEBOV was reported from Uganda in 2011 (WHO 2011).

- Ebola haemorrhagic fever in Sudan 2004: The epicenter of this small outbreak of 17 cases and seven deaths (CFR of $41.2 \%$ ) was the town of Yambio, near to the two previous Ebola sites (Nzara and Maridi) (Onyango et al. 2007). The outbreak started with the admission of a 27-year-old man to Yambio hospital with fever and haemorrhagic manifestations. The onset of symptoms started on 15 April 2004. The outbreak was contained rapidly with the establishment of infection control measures, thanks to the early recognition and confirmation of the outbreak by the Kenya Medical Research Institute (KEMRI).

\section{Etiology}

Ebola virus belongs to the family Filoviridae, in the order Mononegavirales which includes Rhabdoviridae and Paramyxoviridae. The virion is pleomorphic, producing ' $U$ 'shaped, ' 6 '-shaped, or circular forms but the predominant forms of the virion most frequently seen by electron microscope are long tubular structures. It contains one molecule of linear, single-stranded, negative-sense RNA of $4.2 \times 10^{6} \mathrm{Da}$.

The virus was first recognised in 1976 when two unrelated EHF outbreaks occurred $800 \mathrm{~km}$ apart in northern Zaire (Yambuku) and southern Sudan (Nzara or Maridi) (WHO 1978a, 1978b). It was given the name 'Ebola' after the small river near the catholic mission of Yambuku, the epicenter of the 1976 EHF outbreak.

Ebola virus is not restricted to Africa. A new species, REBOV, was described in cynomolgus monkeys (Macaca fascicularis) imported from the Philippines (Manila) to a quarantine facility in Reston, USA in 1989. Subsequently, REBOV has been re-isolated from cynomolgus monkeys and domestic pigs in the Philippines (Barrette et al. 2009).

\section{Transmission}

In most outbreaks, Ebola virus is introduced into human populations via the handling of infected animal carcasses. In these cases, the first source of transmission is an animal found dead or hunted in the forest, followed by person-toperson transmission from index case to family members or health-care staff. Animal-to-human transmission occurs when people come into contact with tissues and bodily fluids of infected animals, especially with infected nonhuman primates (Leroy et al. 2004). Transmission has been reported in Côte d'Ivoire where an ethologist was infected through handling an infected, dead chimpanzee in the Taï Forest (Le Guenno et al. 1995). It was confirmed that the deaths of chimpanzees were indeed due to Ebola virus. In Gabon and the Republic of the Congo, outbreaks in humans were associated with extensive deaths of chimpanzees and gorillas (Rouquet et al. 2005). In contrast, the animal source of infection during the DRC, Uganda and Sudan outbreaks has never been detected. However, when analysing the risk factors for primary transmission of EBOV from a broad anthropological point of view, it is noticeable that the increase in Ebola outbreak since 1994 is frequently associated with drastic changes in forest ecosystems in tropical Africa. The perturbation of these ecosystems due to extensive deforestation and human activities in the depth of the forests may have promoted direct or indirect contact between humans and a natural reservoir of the virus. EBOV infection has therefore been related to human economic activities like hunting (young hunters infected by a chimpanzee in the forest near Mayibout, Gabon in 1996), farming (the charcoal maker in the forest near Kikwit, DRC in 1995) and gold digging (in Minkebé Forest, Gabon in 1994). In some cases, as in Mweka (DRC), EHF outbreaks seemed to be linked to the hunting of bats for bush meat (Leroy et al. 2009). Rarely, scientific activities have resulted in primary EBOV infection, for example, in the case of the ethologist who was involved in wildlife studies in the Taï Forest in 1994. These examples show clearly that certain economic activities, which many populations depend on for their survival, are risk factors for EBOV infection. This finding should be taken into account when public health measures need to be implemented in EBOV-endemic areas. Regarding human-to-human viral transmission, infection occurs in community and hospital settings through direct contact with infected fluids (blood, secretions and excretions) or tissues of an acute patient or through direct contact with contaminated materials. Any clustering of deaths in the same family pointed to EHF during the larger outbreaks. In the community setting, new infections were related to the ministration of funeral rites, which involve ritual cleansing of the cadaver and removal of hair, finger nails, toe nails and clothing before burial. People visiting or taking care of infected persons in their homes or in hospitals also risk being exposed to Ebola infections.

However, we have observed major differences in EBOV transmission cycles between community-based outbreaks and hospital-based outbreaks. When Ebola virus is introduced into a village, the outbreak seems to end spontaneously with limited generations of cases. As shown for the DRC epidemics in Table 1, Ebola virus was introduced into 55 villages around Yambuku (1976) and 25 villages around Kikwit (1995). The majority of the affected villages reported less than ten cases each. Similarly, the chain of transmission of EHF in the village of Ekata in Gabon was very short after the exposure of four brothers to dead animals in 2001. In contrast, a hospital setting with low standards of hygiene and sanitation rapidly becomes a source of epidemic amplification, especially if barrier-nursing techniques and universal hygiene measures are not observed by health workers. As a consequence, these nosocomial outbreaks are characterised by a relatively high proportion of deaths amongst health care workers. Ironically, it was the excessive fatalities amongst health care workers in Kikwit hospital in 1995 that brought the outbreak to the attention of the public health authorities. From this observation, it is possible that EHF infections are not as rare as generally thought. Isolated cases may frequently happen in the community without being reported. In support of this hypothesis, several epidemiological sero-surveys reported high prevalence of Ebola antibodies in communities in the absence of reports of Ebola outbreaks (Becquart et al. 2010; Busico et al. 1999; Gonzalez et al. 2000). Because IgG 
TABLE 1: Distribution of Ebola cases in the affected villages in Democratic Republic of the Congo.

\begin{tabular}{|c|c|c|c|c|}
\hline \multirow{3}{*}{$\begin{array}{l}\text { Number of } \\
\text { cases }\end{array}$} & \multicolumn{4}{|c|}{ Number of affected villages } \\
\hline & \multicolumn{2}{|c|}{ Yambuku (1976) } & \multicolumn{2}{|c|}{ Kikwit (1995) } \\
\hline & Number & $\%$ & Number & $\%$ \\
\hline 1 & 17 & 30.9 & 15 & 60 \\
\hline $2-5$ & 18 & 32.7 & 10 & 40 \\
\hline $6-9$ & 12 & 21.8 & 0 & - \\
\hline $10-14$ & 4 & 7.3 & 0 & - \\
\hline 15-19 & 1 & 1.8 & 0 & - \\
\hline $20-29$ & 1 & 1.8 & 0 & - \\
\hline $30+$ & 2 & 3.7 & 0 & - \\
\hline Total & 55 & - & 25 & - \\
\hline
\end{tabular}

antibodies are known to cross-react amongst Ebola species (MacNeil, Reed \& Rollin 2011), this high seroprevalence may be the outcome of exposure to yet unknown, less pathogenic or non-pathogenic variants of Ebola virus.

Sexual transmission has been suggested in humans since filoviruses can be found in semen (Bausch et al. 2007). Aerosol infection is questioned since people sharing the same space with infected persons do not contract the infection even though aerosol infection of NHP has been demonstrated in the laboratory (Leffel \& Reed 2004).

\section{Ecology}

Tropical rain forests in Africa constitute a common ecosystem for Ebola virus emergence (i.e. the Western Congo Swamp Forests near Yambuku, Taï Forest in Côte d'Ivoire and Minkebé Forest in Gabon), providing rich animal biodiversity, and epidemics appear to be seasonal. Documented human and non-human EHF outbreaks occurred mainly during wet seasons, marked by fruit abundance. The index case of the 1995 EHF outbreak in Kikwit fell ill in January and the 1994 EHF outbreak amongst chimpanzees in the Tai forest occurred in November, at the end of the wet season.

The natural reservoir of infection remains unknown, but the virus clearly has a zoonotic origin. In some outbreaks where information is available, the human index cases have invariably had direct contact with gorillas, chimpanzees, antelope or bats.

The search for a reservoir of EBOV has been very aggressive. Although great apes are generally involved in EHF outbreaks, NHPs are not thought to be natural reservoirs but, rather, susceptible hosts (Table 2) based on the sudden sharp decline in populations of the great apes in Gabon and the Republic of Congo which coincided with EBOV outbreaks in humans (Pourrut et al. 2005). Several other animal and plant species have been investigated for susceptibility and to determine a natural reservoir of EBOV. During the 1976-1979 EHF outbreaks, several ecological studies were conducted in order to identify the reservoir of the virus in nature. Studies were conducted on plants eaten by guinea pigs (Tandala, DRC), on monkeys (Yambuku, DRC) and on bats (Nzara, Sudan) but without success. Further ecological investigations using modern technologies, were carried out during the subsequent episodes of EHF outbreaks (1994-2010) especially in Kikwit, where thousands of rodents, insects and birds were screened. These investigations have not been successful for various reasons, one being that they are usually implemented retrospectively, several weeks or months after the index case has been infected by a putative reservoir. It is possible that by that time the putative reservoirs may have moved to another site. A surveillance system capable of early detection of Ebola cases could allow animal reservoir studies in 'real time', which is not always easy in remote places in African forests.

Experimental studies provide a more convenient, alternative method to identify candidate animal reservoirs and need not rely on an actual outbreak. Studies on 33 varieties of 24 species of plants and on 19 species of vertebrates and invertebrates experimentally infected with Ebola virus gave the first evidence that both insectivorous and frugivorous bats can support the replication and circulation of EBOV (Swanepoel et al. 1996). This evidence along with reports of bat exposures for some of the Ebola index cases directed the research toward the bats as potential reservoirs. Indeed, an ecological survey revealed the presence of ZEBOV-specific antibodies in six bat species caught in the field (Epomops franqueti, Hypsignathus monstrosus, Myonycteris torquata, Micropteropus pusillus, Mops condylurus and Rousettus aegyptiacus) (Pourrut et al. 2005). Viral nucleic acid sequences of Ebola virus was also found in three species of fruit bat during the 2001-2003 outbreaks in Gabon and Republic of the Congo (Leroy et al. 2005). These studies were pre-dated by the ecological investigation of the 1998-2000 Marburg heamorrhagic fever outbreak in Durba village in northeastern DRC, which consisted of repeated occurrences of short transmission chains arising in workers in Goroumbwa Mine where large numbers of bats roosted (Swanepoel et al. 2007).

TABLE 2: Documented outbreaks of Ebola virus amongst non-human primates and swine (1980-2005) in Africa.

\begin{tabular}{llll}
\hline Year & Non-human primates or swine & Location & Comments \\
\hline $1989-1990$ & Macaques & Reston, VA, USA & Discovery of a new species: Ebola Reston (REBOV) \\
1992 & Macaques & Sienna, Italy & \\
1996 & Macaques & Alice, TX, USA & \\
2009 & Swine & Philippines & Discovery of a new species: Ebola Côte dôlvoire (CIEBOV) \\
1994 & Chimpanzees & Tai Forest, Côte dôlvoire & Ebola Zaire (ZEBOV) \\
1996 & Chimpanzees & Mayibout 2, Gabon & Ebola Zaire (ZEBOV) \\
$2001-2002$ & Gorillas & Mendemba, Gabon & Ebola Zaire (ZEBOV) \\
2003 & Gorillas & Mbomo, Republic of the Congo & Ebola Zaire (ZEBOV) \\
2005 & Gorillas & Mbomo-Kellé, Republic of the Congo & Ebola Zaire (ZEBOV) \\
& & Etumbi, Republic of the Congo & \\
\hline
\end{tabular}


A hypothesis of recurrent introductions of infection into humans from a natural source was supported by the finding that multiple genetic lineages of virus circulated during the outbreak. Diverse genetic lineages of Marburg virus were detected in Egyptian fruit bats, R. aegyptiacus, and two species of insectivorous bat in the mine (Rhinolophus eloquens, the eloquent horse-shoe bat, and Miniopterus inflatus, the greater long-fingered bat) and, furthermore, these lineages corresponded to the ones isolated from the humans in Durba. Due to the complexity of laboratory testing of specimens collected from animals potentially infected with filoviruses and the necessity to conduct the testing under biosafety level four (BSL-4) conditions, the results of the study were only published seven years later but in the meantime had been presented at numerous international scientific meetings and significantly assisted in focusing filovirus ecology studies on bats as putative reservoir species.

In this context, an Ebola ecology expedition was organised in May 2011 (Figures 1 and Figure 2) to undertake a preliminary study in Luebo, DRC where recent outbreaks of Ebola haemorrhagic fever occurred, and where cases of the disease were linked to catching bats for human consumption (Leroy et al. 2009). The expedition aimed at testing the techniques and materials to be used during a larger international expedition planned to take place early the following year. Forty-four specimens of different bat species were sampled, including those which are strongly implicated as potential reservoirs of filoviruses (e.g. H. monstrosus). Blood and tissues from various organs were collected and brought to the NICD or NHLS for laboratory testing in the recently commissioned maximum security laboratory (BSL-4), which had undergone extensive and protracted upgrading and refurbishment. This maximum security laboratory constitutes a strategically important research resource for preparedness training and response to outbreaks of dangerous pathogens, but will also greatly support efforts by African scientists to unravel the elusive nature of filovirus transmission cycles (Figure 3). Experimental inoculation studies have recently been conducted at this facility with filoviruses and Egyptian fruit bats.

Despite the finding of Ebola virus nucleic acid, antigen or antibodies in bats, EBOV has never been isolated from them or any putative animal reservoir so far. However, the isolation of replicative Marburg virus, another member of the filovirus family, from wild fruit bats (Towner et al. 2009), reinforces the assumption that bats are strong EBOV reservoir candidates. Based on this hypothesis, a model of virus dissemination has been proposed: bats can transmit the virus either directly to humans and NHPs or through an unknown vector as illustrated in Figure 4.

\section{Clinical features}

The onset of the disease is abrupt after an incubation period of two to 21 days. The clinical features can be divided into four main phases as follows, (1) Phase A. Influenza-like syndrome: The onset is abrupt with non-specific symptoms or signs such as high fever, headache, arthralgia, myalgia, sore throat, and malaise with nausea. (2) Phase B. Acute (day

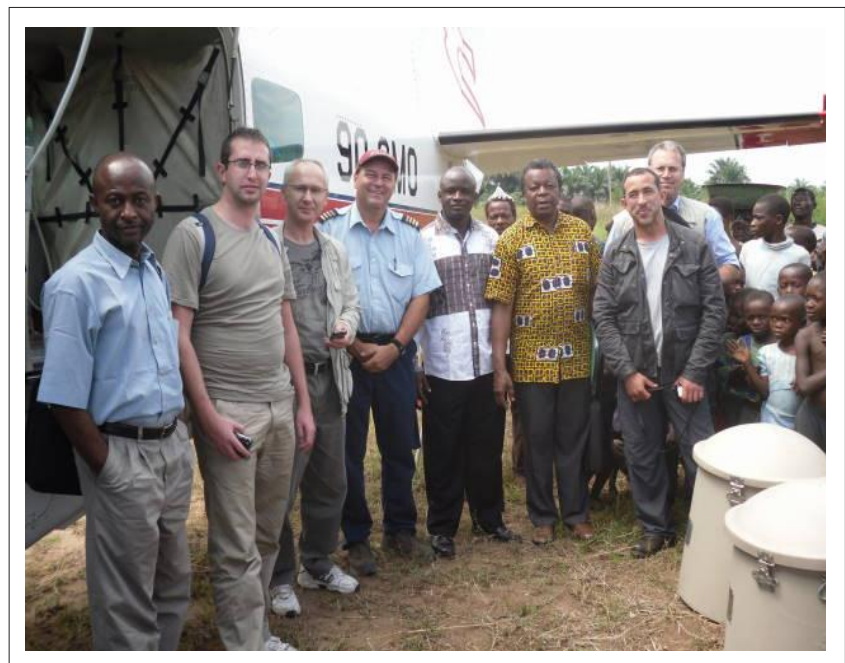

Source: Photograph provided by authors

The expedition was supported by the World Health Organisation (WHO), the Southern African Centre for Infectious Disease Surveillance (SACIDS), the Institut National de Recherce Biom Recherche Biomedicale (INRB, DRC), and the National Institute for Communicable Diseases
of the National Health Laboratory Service (NICD/NHLS, RSA).

From left to right: Dr Justin Masumu (SACIDS), Dr Petrus Jansen van Vuren (NICD/NHLS), Prof. Janusz Paweska (NICD/NHLS), Mr David Francis (MAF pilot), Dr Jean-Luc Biampata (CPC Luebo hospital, host), Prof. Jean-Jacques Muyembe (INRB), Mr Kamal Aitikhlef (WHO) and Mr Alan Kemp (NICD/NHLS).

FIGURE 1: The Ebola ecology expedition team arriving in Luebo, Democratic Republic of the Congo, May 2011.

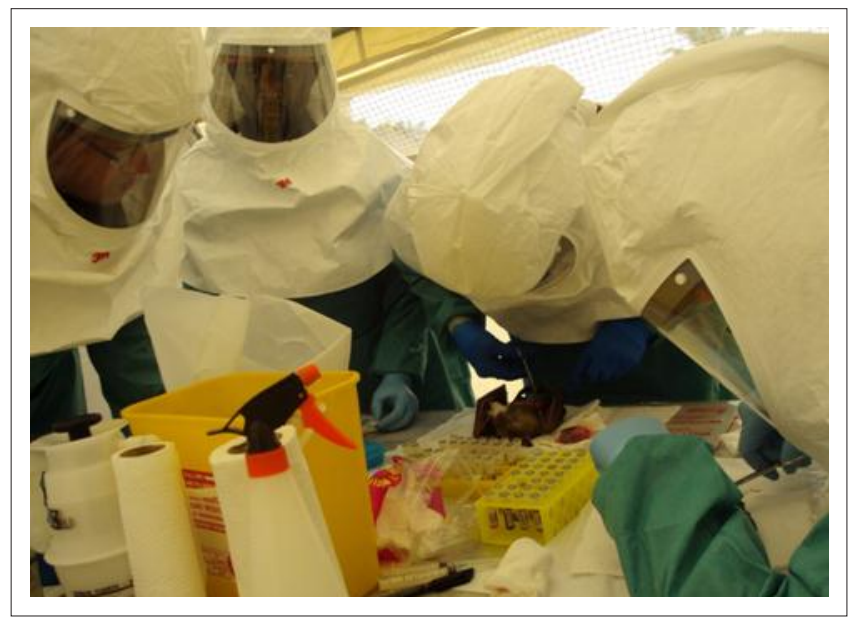

Source: Photograph provided by authors

FIGURE 2: Dissection of wild-caught bats. Field laboratory deployed during Ebola ecology study in Luebo, Democratic Republic of the Congo, May 2011.



Source: Photograph provided by authors

FIGURE 3: Processing and testing of blood and tissues from bats collected during the 2011 Ebola ecology expedition to Luebo, Democratic Republic of the Congo in biosafety level four facility in Sandringham-Johannesburg, South Africa. 
1-6): Persistent fever not responding to antimalaria drugs or to antibiotics, headache, intense fatigue, followed by diarrhea and abdominal pain, anorexia and vomiting. (3) Phase C. Pseudo-remission (day 7-8): During this phase the patient feels better and seeks food. The health situation presents with some improvement. Some patients may recover during this phase and survive from the disease and (4) Phase D. Aggravation (day 9): In many if not most cases, the health status gets worse. The following symptoms may be observed:

- respiratory disorders: dyspnea, throat and chest pain, cough, hiccups

- symptoms of haemorrhagic diathesis: bloody diarrhoea, haematemesis, conjunctival injection, gingival bleeding, nosebleeds and bleeding at the site of injection consistent with disseminated intravascular coagulation (Figure 5)

- skin manifestations: petaechiae (not so obvious on black skin), purpura (morbiliform skin rash)

- neuro-psychiatric manifestations: prostration, delirium, confusion, coma

- cardio-vascular distress and hypovolaemic shock (death).

From these clinical manifestations it is obvious that EHF may mimic many other tropical diseases like malaria, typhoid fever or yellow fever at the start of the disease. In most outbreaks, recognition of the disease is delayed because physicians are not

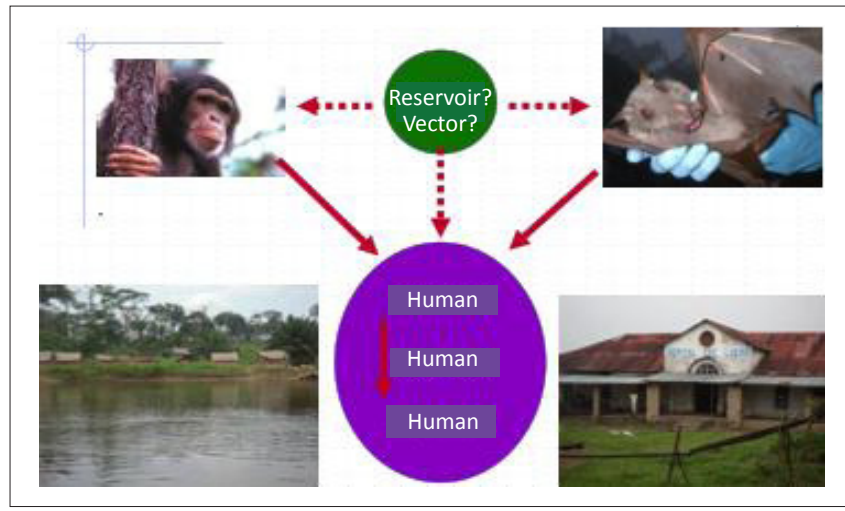

FIGURE 4: The potential chains of transmission of Ebola virus may be described as involving 3 stages, from primates or bats to humans (especially hunters) in the wild (index case), from index case to secondary cases (introduction into the domestic environment) and from patient to healthcare personnel in the clinical setting. Whilst primates and fruit bats are known to be sources of Ebola virus in nature, the reservoir has not yet been identified with any certainty.

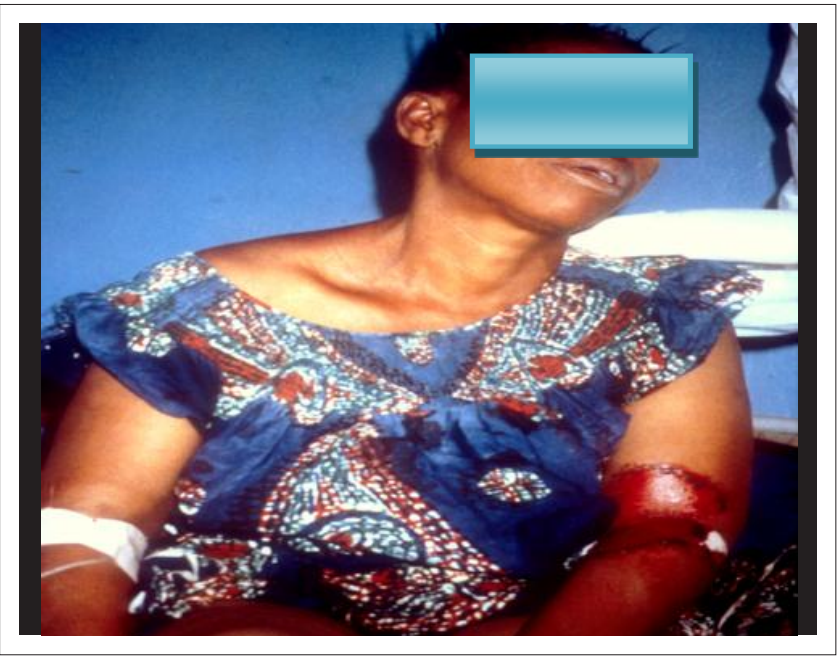

Source: Photograph provided by authors

FIGURE 5: Ebola patient with haemorrhagic diathesis at transfusion and injection sites. accustomed to this new illness and the symptoms are generally non-specific. Outside the epidemic context, it appears quite impossible to recognise the first Ebola case in an outbreak on clinical grounds only. Suspicion of EHF is only possible later during the aggravation phase.

\section{Diagnosis}

Early laboratory confirmation of suspected clinical haemorrhagic fever cases is essential to implement appropriate control measures. Definitive diagnosis of suspected cases of EHF is usually made by PCR detection and virus isolation on Vero cells. As a class- 4 pathogen, Ebola virus culture requires a maximum containment facility.

Additional laboratory diagnostic tests include ELISAs for the detection of Ebola IgG- and IgM-specific antibodies and virus antigens; more specialised molecular testing is also available but is not readily available in the usual clinical setting.

In Africa, laboratory confirmation of Ebola cases has been challenging and early recognition of the first outbreaks were severely hampered as a result. Because the disease was poorly known or rare, laboratory investigations were oriented towards the more common, endemic pathogens in the area.

Initially, Salmonella typhi and yellow fever virus were suspected to be responsible for the 1976 Yambuku outbreak. Blood samples collected for cultures (that remained negative), Widal tests and liver specimens presented for pathological examination showed inconsistent results: some specimens gave evidence of yellow fever whilst others were compatible with liver congestion. The Yambuku outbreak was finally confirmed by viral culture at the Institute of Tropical Medicine in Antwerp thanks to blood samples collected from a Belgian nun who fell ill in Yambuku and was transferred to Ngaliema hospital in Kinshasa. For the Kikwit cases in 1995, a nosocomial bloody diarrhea outbreak caused by Shigella dysenteriae or S. typhi was initially considered, as these diseases were endemic to Kikwit. Preliminary bacteriological investigations were conducted on 97 stool samples and nine blood cultures. Only four stool specimens tested positive for Shigella species and all blood cultures remained negative. The index case of this nosocomial outbreak was a 36-yearold laboratory technician who underwent a laparotomy in the Kikwit general referral hospital for suspected perforated bowel after a protracted febrile syndrome with headache, myalgia and asthaenia. Contact with his body fluids appeared to be the main mode of transmission for the subsequent secondary cases, suggesting that the disease was a viral haemorrhagic fever. To confirm this hypothesis, 14 blood specimens from acutely ill persons were collected and sent to the Institute of Tropical Medicine in Antwerp, Belgium. The evidence of acute Ebola infection was obtained in all specimens either by viral isolation, antigen-detection ELISA or RT-PCR.

Since 1994, the incidence of Ebola outbreaks increased and, as a consequence, the awareness of the disease has improved and facilities capable of diagnosing EHV were established in Africa. National Public Health laboratories in endemic countries like Uganda (UVRI), Kenya (KEMRI) and Gabon 
(CIRMF) have already developed capacities to diagnose EHF by ELISA and RT-PCR. South Africa is the only African country with a maximum containment, enclosed suit laboratory where all class- 4 viral pathogens can be handled safely.

After the last Ebola outbreak in Kaluamba, DRC (2008-2009), the Ebola diagnostic technologies of ELISAs for the detection of antigens and $\operatorname{IgM}$ antibody, and RT-PCR have been transferred to the INRB in Kinshasa.

\section{Treatment}

Managing Ebola patients in the African setting was a major challenge because there was no effective antiviral drug and no specific vaccine available. Only supportive care could be administered, to sustain cardiac and renal functions with prudent use of perfusion. Oral rehydration was recommended but sometimes not realistic because of throat pain, vomiting and intense fatigue. The main objective was to provide optimal care to the patient with maximum protection of the medical and nursing staff. For that purpose, medical and nursing staff had been trained in donning and removing personal protective equipment (PPE) and applying barrier-nursing procedures.

In a clinical experiment conducted late in the 1995 Ebola outbreak in Kikwit, human convalescent blood was used for passive immunisation to treat patients that had been infected naturally with ZEBOV; seven out of eight patients who received blood transfusion from convalescent Ebola patients survived (Mupapa et al. 1999). Such experiments, unfortunately, have not been repeated in further outbreaks because in vitro studies showed that antibodies against Ebola had no neutralising activities. In addition, although monoclonal antibodies to the glycoprotein of Ebola virus showed protective and therapeutic properties in mice, they failed to protect NHP (Gupta et al. 2001; Oswald et al. 2007).

Since Ebola virus is generally considered as a potential biological weapon, it is urgent to develop effective antiviral drugs and vaccines. The ideal is to develop a candidate vaccine able to confer interspecies cross-protection against ZEBOV, SEBOV, BEBOV and unknown Ebola virus species.

\section{Control measures}

The corner-stone for controlling an outbreak of EHF is to interrupt the viral transmission chain. In order to reduce transmission, several strict public health measures need to be implemented as quickly as possible, including isolation of patients, barrier precautions and identification and tracking of all contacts. Most of the time, outbreaks are managed by a core structure called the International Committee on Scientific and Technical Coordination, under the aegis of the World Health Organisation (WHO). This committee is in charge of implementing control measure activities on a daily basis and has the following working subgroups:

- Co-ordination committee, which is responsible for all epidemic response activities, chair daily meetings and write reports for public health authorities and health partners.
- The patient management team is involved in the isolation of clinical cases in a quarantine ward, training of medical and relief personnel on the proper use of protective equipment (gloves, gowns, masks etc.), and providing medical care based on symptomatic therapy to maintain the vital respiratory, cardio-vascular and renal functions. The non-governmental organisation, Doctors Without Borders (MSF), has developed expertise in this field from involvement in outbreak response.

- The hygiene and sanitation team is in charge of disinfection and burial of all Ebola and non-Ebola dead bodies under safe conditions. Local Red Cross volunteers usually perform these activities.

- The epidemiological surveillance team is in charge of active and passive case finding, contact tracing and rumorverification of suspect cases or deaths in the community.

- Social mobilisation and health education are critical for controlling an Ebola outbreak since resistance from the community to freely provide information on patients, deaths and contacts are commonplace. Ebola haemorrhagic fever outbreaks have many socio-cultural aspects that need to be studied deeply as communities can reject the anti-epidemic control measures imposed by the international scientific and technical committee. The existence of rumours and legends related to the outbreaks could obscure the viral nature of the disease. Sometimes the anti-epidemic control measures needed to be adapted to the local culture, for example, funeral practices as in the 2003 Ebola outbreak in Republic of the Congo (Hewlett et al. 2005). The members of this team should include medical anthropologists, local Red Cross volunteers and opinion leaders such as teachers, religious groups, et cetera, for public sensitisation, education and information.

- The logistic support team is in charge of providing any administrative, logistic and technical support to the other teams, such as coordination of secretariat, transport and communication.

- The laboratory and research team is in charge of collecting, storing and shipping of clinical samples for diagnostic confirmation. This team is also responsible for ecological studies to determine the origins of an outbreak.

- Psychosocial support for the affected family or families has been neglected during previous outbreaks, but this issue has become more and more important due to stigmatisation of survivors and their families by the community.

\section{Conclusion}

Formerly sporadic, with high case fatality rates (up to 90\%), the deadly Ebola haemorrhagic fever outbreaks are becoming more and more frequent in Africa, mostly in relation to increasing contact with infected wildlife. Previous epidemics were detected after a long delay, especially because of the remoteness of the epidemic focus, the lack of laboratory facilities and the poor knowledge of the disease by doctors and nurses, who confused Ebola disease with malaria or typhoid fever.

The more recent epidemics in Yambio (2004) and Kaluamba (2008) resulted in low CFRs of $41.2 \%$ and $43.8 \%$, respectively. 
This is mainly related to the early detection of the outbreaks followed by a prompt and vigorous response from public health authorities and their partners.

Ebola haemorrhagic fever epidemics constitute a significant public health concern in Africa and an effective vaccine is needed urgently. Such a vaccine would primarily benefit doctors, nurses and field epidemiologists working in endemic countries. The second target group would be the scientists working with Ebola virus as well as veterinarians and those involved in wildlife conservation in endemic areas. Since its discovery in 1976, much is known about Ebola virology, physiopathology, clinical features and epidemiology, but the missing link certainly remains the virus reservoir in nature. The current research focused on bats as putative ZEBOV reservoirs has to be reinforced and extended to the reservoirs of other Ebola species.

\section{References}

Amblard, J., Obiang, P., Edzang, S., Prehaud, C., Bouloy, M. \& Le Guenno, B., 1997 'Identification of the Ebola virus in Gabon in 1994', Lancet 349, 181-182. http:// dx.doi.org/10.1016/S0140-6736(05)60984-1

Baron, R.C., McCormick, J.B. \& Zubeir, O.A., 1983, 'Ebola virus disease in southern Sudan: hospital dissemination and intrafamilial spread', Bulletin of the World Sudan: hospital dissemination and intrafamilial s
Health Organization 61, 997-1003. PMid:6370486

Barrette, R.W., Metwally, S.A., Rowland, J.M., Xu, L., Zaki, S.R., Nichol, S.T. et al., 2009 'Discovery of swine as a host for the Reston ebolavirus', Science 325, 204-206. http://dx.doi.org/10.1126/science.1172705, PMid:19590002

Bausch, D.G., Towner, J.S., Dowell, S.F., Kaducu, F., Lukwiya, M., Sanchez, A. et al., 2007 , 'Assessment of the risk of Ebola virus transmission from bodily fluids and fomites', Journal of Infectious Diseases 196 (Supplement 2), S142-S147. http:// dx.doi.org/10.1086/520545, PMid:17940942

Becquart, P., Wauquier, N., Mahlakoiv, T., Nkoghe, D., Padilla, C., Souris, M. et al., 2010, 'High prevalence of both humoral and cellular immunity to Zaire ebolavirus among rural populations in Gabon', $P$ LoS One 5, e9126. http://dx.doi.org/10.1371/ journal.pone.0009126, PMid:20161740

Busico, K.M., Marshall, K.L., Ksiazek, T.G., Roels, T.H., Fleerackers, Y., Feldmann, H. et al., 1999, 'Prevalence of IgG antibodies to Ebola virus in individuals during an Ebola outbreak, Democratic Republic of the Congo, 1995', Journal of Infectious Ebola outbreak, Democratic Republic of the Congo, 1995', Journal of Infectious
Diseases 179 (Supplement 1), S102-S107. http://dx.doi.org/10.1086/514309, Diseases 179

Feldmann, H. \& Geisbert, T.W., 2011, 'Ebola haemorrhagic fever', Lancet 377, 849862. http://dx.doi.org/10.1016/S0140-6736(10)60667-8

Feldmann, H., Geisbert, T.W., Jahrling, P.B., Klenk, H.D., Netesov, S.V., Peters, C.J. et al., 2005, 'Filoviridae', in C. Fauquet, M.A. Mayo, J. Maniloff, U. Desselberger \& L.A. Ball (eds.), Virus Taxonomy: VIIIth Report of the International Committee on Taxonomy of Viruses, pp. 645-653, Elsevier/Academic Press, London.

Formenty, P., Leroy, E.M., Epelboin, A., Libama, F., Lenzi, M., Sudeck, H. et al., 2006, 'Detection of Ebola virus in oral fluid specimens during outbreaks of Ebola virus hemorrhagic fever in the Republic of Congo', Clinical Infectious Diseases 42, 15211526. http://dx.doi.org/10.1086/503836, PMid:16652308

Georges-Courbot, M.C., Lu, C.Y., Lansoud-Soukate, J., Leroy, E. \& Baize, S., 1997a, 'Isolation and partial molecular characterisation of a strain of Ebola virus during a recent epidemic of viral haemorrhagic fever in Gabon', Lancet 349, 181. http:// dx.doi.org/10.1016/S0140-6736(05)60983-X

Georges-Courbot, M.C., Sanchez, A., Lu, C.Y., Baize, S., Leroy, E., Lansout-Soukate, J. et al., 1997b, 'Isolation and phylogenetic characterization of Ebola viruses causing
different outbreaks in Gabon', Emerging Infectious Diseases 3, 59-62. http:// dx.doi.org/10.3201/eid0301.970107, PMid:9126445

Gonzalez, J.P., Nakouné, E., Slenczka, W., Vidal, P. \& Morvan, J.M., 2000, ‘Ebola and Marburg virus antibody prevalence in selected populations of the Central African Republic', Microbes and Infection 2, 39-44. http://dx.doi.org/10.1016/S1286 4579(00)00287-2

Groseth, A., Feldmann, H. \& Strong, J.E., 2007, 'The ecology of Ebola virus', Trends in Microbiology 15, 408-416. http://dx.doi.org/10.1016/j.tim.2007.08.001, PMid:17698361

Guimard, Y., Bwaka, M.A., Colebunders, R., Calain, P., Massamba, M., De Roo, A. et al., 1999, 'Organization of patient care during the Ebola hemorrhagic fever epidemic in Kikwit, Democratic Republic of the Congo, 1995', Journal of Infectious Diseases 179 (Supplement 1), S268-S273. http://dx.doi.org/10.1086/514315, PMid:9988194

Gupta, M., Mahanty, S., Bray, M., Ahmed, R. \& Rollin, P.E., 2001, 'Passive transfer of antibodies protects immunocompetent and imunodeficient mice against lethal Ebola virus infection without complete inhibition of viral replication', Journal of Virology 75, 4649-4654. http://dx.doi.org/10.1128/JVI.75.10.4649-4654.2001, PMid:11312335

Hewlett, B.S., Epelboin, A., Hewlett, B.L. \& Formenty, P., 2005, 'Medical anthropology and Ebola in Congo: cultural models and humanistic care', Bulletin de la Société de Pathologie Exotique 98, 230-236. PMid:16267966
Heymann, D.L., Weisfeld, J.S., Webb, P.A., Johnson, K.M., Cairns, T. \& Berquist, H., 1980, 'Ebola hemorrhagic fever: Tandala, Zaire, 1977-1978', Journal of H., 1980, Ebola hemorrhagic fever: Tandala, Zaire, 1977-1978, Journal of
Infectious Diseases 142, 372-376. http://dx.doi.org/10.1093/infdis/142.3.372, Infectious Dise

Khan, A.S., Tshioko, F.K., Heymann, D.L., Le Guenno, B., Nabeth, P., Kerstiens, B. et al., 1999, 'The re-emergence of Ebola hemorrhagic fever, Democratic Republic of the Congo, 1995', Journal of Infectious Diseases 179 (Supplement 1), S76-S86. http:// dx.doi.org/10.1086/514306, PMid:9988168

Lamunu, M., Lutwama, J.J., Kamugisha, J., Opia, A., Nambooze, J., Ndayimirije, N. et al., 2004, 'Containing a haemorrhagic fever epidemic: The Ebola experience in Uganda (October 2000 - January 2001)', International Journal of Infectious Diseases 8, 27-37. http://dx.doi.org/10.1016/j.ijid.2003.04.001, PMid:14690778

Leffel, E.K. \& Reed, D.S., 2004, 'Marburg and Ebola viruses as aerosol threats', Biosecurity and Bioterrorism: Biodefense Strategy, Practice, and Science 2, 186191.

Le Guenno, B., Formenty, P., Wyers, M., Gounon, P., Walker, F. \& Boesch, C., 1995 'Isolation and partial characterisation of a new strain of Ebola virus', Lancet 345 , Isolation and partial characterisation of a new strain of Ebola virus
1271-1274. http://dx.doi.org/10.1016/S0140-6736(95)90925-7

Leroy, E.M., Epelboin, A., Mondonge, V., Pourrut, X., Gonzalez, J.P., Muyembe-Tamfum, J.J. et al., 2009, 'Human Ebola outbreak resulting from direct exposure to fruit bats in Luebo, Democratic Republic of Congo, 2007', Vector-borne and Zoonotic Diseases 9, 723-728. http://dx.doi.org/10.1089/vbz.2008.0167, PMid:19323614

Leroy, E.M., Gonzalez, J.P. \& Baize, S., 2011, 'Ebola and Marburg haemorrhagic fever viruses: major scientific advances, but a relatively minor public health threat for Africa', Clinical Microbiology and Infection 17, 964-976. http://dx.doi. org/10.1111/j.1469-0691.2011.03535.x, PMid:21722250

Leroy, E.M., Kumulungui, B., Pourrut, X., Rouquet, P., Hassanin, A., Yaba, P. et al., 2005, 'Fruit bats as reservoirs of Ebola virus', Nature 438, 575-576. http://dx.doi. org/10.1038/438575a, PMid:16319873

Leroy, E.M., Rouquet, P., Formenty, P., Souquière, S., Kilbourne, A., Froment, J.M. et al., 2004, 'Multiple Ebola virus transmission events and rapid decline of
central African wildlife', Science 303, 387-390. http://dx.doi.org/10.1126/ central African wildlife', Science
science.1092528, PMid:14726594

Leroy, E.M., Souquiere, S., Rouquet, P. \& Drevet, D., 2002, 'Re-emergence of ebola haemorrhagic fever in Gabon', Lancet 359, 712. http://dx.doi.org/10.1016/S01406736(02)07796-6

MacNeil, A., Reed, Z. \& Rollin, P.E., 2011, 'Serologic cross-reactivity of human IgM and IgG antibodies to five species of Ebola virus', PLoS Neglected Tropical Diseases 5, e1175. http://dx.doi.org/10.1371/journal.pntd.0001175, PMid:21666792

Mupapa, K., Massamba, M., Kibadi, K., Kuvula, K., Bwaka, A., Kipasa, M. et al., 1999, 'Treatment of Ebola hemorrhagic fever with blood transfusions from convalescent patients', Journal of Infectious Diseases 179 (Supplement 1), S18-S23. http:// dx.doi.org/10.1086/514298, PMid:9988160

Nkoghe, D., Kone, M.L., Yada, A. \& Leroy, E., 2011, 'A limited outbreak of Ebola haemorrhagic fever in Etoumbi, Republic of Congo, 2005', Transactions of the Royal Society of Tropical Medicine and Hygiene 105, 466-472. http://dx.doi. org/10.1016/j.trstmh.2011.04.011, PMid:21605882

Onyango, C.O., Opoka, M.L., Ksiazek, T.G., Formenty, P., Ahmed, A., Tujkei, P.M. et al. 2007, 'Laboratory diagnosis of Ebola hemorrhagic fever during an outbreak in Yambio, Sudan, 2004', Journal of Infectious Diseases 196 (Supplement 2), S193Yambio, Sudan, 2004', Journal of Infectious Diseases 196
S198. http://dx.doi.org/10.1086/520609, PMid:17940949

Oswald, W.B., Geisbert, T.W., Davis, K.J., Geisbert, J.B., Sullivan, N.J., Jahrling, P.B. et al., 2007, 'Neutralizing antibody fails to impact the course of Ebola virus infection in monkeys', PLoS Pathogens 3, e9. http://dx.doi.org/10.1371/journal. ppat.0030009, PMid: 17238286

Pourrut, X., Kumulungui, B., Wittmann, T., Moussavou, G., Délicat, A., Yaba, P. et al., 2005 , 'The natural history of Ebola virus in Africa', Microbes and Infection 7, 10051014. http://dx.doi.org/10.1016/j.micinf.2005.04.006, PMid:16002313

Rouquet, P., Froment, J.M., Bermejo, M., Kilbourne, A., Karesh, W., Reed, P. et al., 2005, 'Wild animal mortality monitoring and human Ebola outbreaks, Gabon and Republic of Congo, 2001-2003', Emerging Infectious Diseases 11, 283-290. http:// dx.doi.org/10.3201/eid1102.040533, PMid:15752448

Swanepoel, R., Leman, P.A., Burt, F.J., Zachariades, N.A., Braack, L.E.O., Ksiazek, T.G. et al., 1996, 'Experimental inoculation of plants and animals with Ebola virus', Emerging Infectious Diseases 2, 321-325. http://dx.doi.org/10.3201/ eid0204.960407, PMid:8969248

Swanepoel, R., Smit, S.B., Rollin, P.E., Formenty, P., Leman, P.A., Kemp, A. et al., 2007, 'Studies of reservoir hosts for Marburg virus', Emerging Infectious Diseases 13, 1847-1851. http://dx.doi.org/10.3201/eid1312.071115, PMid:18258034

Towner, J.S., Amman, B.R., Sealy, T.K., Reeder Carrol, S.A., Comer, J.A., Kemp, A. et al., 2009, 'Isolation of genetically diverse Marburg viruses from Egyptian fruit bats', PLoS Pathogens 5, e1000536. http://dx.doi.org/10.1371/journal.ppat.1000536, PMid:19649327

Towner, J.S., Sealy, T.K., Khristova, M.L., Albariño, C.G., Conlan, S., Reeder, S.A. et al., 2008, 'Newly discovered ebola virus associated with hemorrhagic fever outbreak in Uganda', PLOS Pathogens 4, e1000212. http://dx.doi.org/10.1371/journal. ppat.1000212, PMid:19023410

Walsh, P.D., Abernethy, K.A., Bermejo, M., Beyers, R., De Wachter, P., Akou, M.E. et al., 2003, 'Catastrophic ape decline in western equatorial Africa', Nature 422, 611-614. http://dx.doi.org/10.1038/nature01566, PMid:12679788

WHO, 1978a, 'Ebola haemorrhagic fever in Sudan, 1976. Report of a WHO/ International Study Team', Bulletin of the World Health Organization 56, 247-270. International Stur: 307455

WHO, 1978b, 'Ebola haemorrhagic fever in Zaire, 1976', Bulletin of the World Health Organization 56, 271-293. PMid:307456

WHO, 2011, 'Ebola in Uganda', Global Alert and Response, viewed 04 October 2011, from http://www.who.int/csr/don/2011_05_18/en/index.htm 